Results Our primary measure 'bed days per month occupied by patients with a length of stay of over 30 days' decreased from a mean of 635 bed days/month in 2016-18 to 534 bed days/month in $2018 / 19$, a reduction of $16 \%$. This is equivalent to $>3$ additional beds available on the wards each day.

In 2019 year to date we have sustained this reduction and aim for further improvement. In addition, patient and staff satisfaction with the care of these patients has improved and the rate of readmission was unaffected.

Conclusion Despite increasing medical complexity in our inpatients, and internal and external challenges the rise we had seen in prolonged admissions over recent years is not inevitable. It is possible to significantly reduce length of stay for these patients and simultaneously improve quality of care. Improving services for these children and young people should be a priority for paediatrics in the future and has benefits for patients, families, staff, the institution and the wider population.

\section{G84 IMPROVING BCG VACCINATION REFERRAL OF ADMITTED ELIGIBLE NEWBORN TO 98\% BY JULY 2019}

KJ Jeyasingam, HM McElroy. Neonatology, Medway Maritime Hospital, Medway, UK

\subsection{6/archdischild-2020-rcpch.65}

Aim The development of effective antibiotics and the BCG vaccination has significantly reduced the number of TB cases. The aim of this quality improvement project (QIP) is to improve BCG vaccination referrals for admitted eligible newborns in Hospital to $98 \%$ by June-July 2019, by raising awareness amongst healthcare professionals and improving identification of eligible newborns.

Methodology The aim and objectives were formulated using a driver diagram. A Plan-Do-Study-Act cycle was used to identify suitable changes and outcomes. Euroking database was used to create a spreadsheet with information specific for BCG vaccination eligibility and referral status. Data was collected from May 2018 to May 2019. Resources that raised awareness amongst healthcare professionals, by providing guidance for easier recognition of eligible newborns, were created by working closely with doctors, nurses and midwives.

Result The numbers of missed BCG referrals from May 2018 to Aug 2018 was 10 out of 13 (76. 9\%). From September 2018 to May 2019, it was 18 out of 34 (52.9\%), which showed a reduction of $23.9 \%$ in missed BCG referrals. From September 2018 onwards, doctors were obliged to refer newborns for BCG vaccination.

Questionnaires were sent out in March 2019 to former and current paediatric and non-paediatric doctors. 7 out of 10 questionnaire responses were received. All of the responders found it easy to refer newborns for BCG vaccination and used the WHO list to identify high-risk countries. Paediatric trainees were informed about BCG vaccination referral during their induction, whilst non- paediatric trainees were aware of the referral via this QIP or by speaking to seniors. In May 2019, awareness was raised and random spot checks were done in June and July 2019.The number of missed BCG referrals for June 2019 to July 2019 was 0 out of 2 and $100 \%$ of BCG referrals was achieved.

Conclusion Improving BCG referrals will reduce the time, work and resources needed to chase missed BCG referrals and avoid new cases of TB. This could be achieved with easy access to information, such as the ethnic origins of grandparents/parents of newborns, which will be added to the next antenatal book.

\section{G85 IMPROVING CANNULATION EFFICIENCY IN LEEDS CHILDREN'S HOSPITAL (LCH)}

A Fonfe, K Lotha, T Rance. Paediatrics, Leeds Teaching Hospitals, Leeds, UK

\subsection{6/archdischild-2020-rcpch.66}

Background There was anecdotal evidence that the time to gather equipment for paediatric cannulation was time consuming. This had the potential to create delays in such time-crucial matters as IV antibiotics within 60 minutes in suspected sepsis.

Aim To standardise cannulation trolleys across LCH to improve equipment gathering efficiency.

Method

- Questionnaire to junior doctors to determine how long it equipment gathering takes and number of cannulas inserted per shift.

- Junior doctors were timed gathering all necessary cannulation equipment on all wards

- A pilot cannulation trolley was trialled on the children's assessment unit. Adjustments were made after feedback and photographs of equipment were inserted on the trolley to faciliate appropriate stocking.

- Junior doctors were then timed gathering cannulation equipment with the new trolleys.

- A cannulation trolley champion was nominated for each ward.

- New cannulation trolleys were disseminated across all wards in $\mathrm{LCH}$.

Results

- $88 \%$ of doctors agreed that 'It often takes me longer to find the equipment I need for cannulation than inserted the cannula'.

- 1-6 cannulas are inserted per junior doctor shift.

- Time taken to gather cannulation equipment at baseline 4.21 minutes. With cannulation trolleys 2.12 minutes.

- Based on 1-6 cannulations per doctor per shift, before the trolleys this would take $87-522$ minutes and post-trolleys 43-258 minutes.

Conclusion Introduction of standardised cannulation trolleys has improved efficiency at cannulation preparation and has enabled speedier cannulation especially in time critical circumstances such as sepsis.

\section{G86 IMPROVING DISCHARGE SUMMARY QUALITY IN A GREENFIELD SINGLE ROOM QUATERNARY NEONATAL INTENSIVE CARE UNIT}

${ }^{1,2} \mathrm{~A}$ Anbu Chakkarapani, 'L Chicoine, ${ }^{1} \mathrm{R}$ Soni, ${ }^{1} \mathrm{E}$ Elfaki A Alla, ${ }^{1} \mathrm{~J}$ Powell, ${ }^{1} \mathrm{~B}$ George, ${ }^{1} \mathrm{~L}$ Greig, ${ }^{1,2} \mathrm{~B}$ Lee. 'Division of Neonatology, Department of Pediatrics, Sidra Medicine, Doha, Qatar; ${ }^{2}$ Department of Pediatrics, Weill Cornell Medicine-Q, Doha, Qatar

\subsection{6/archdischild-2020-rcpch.67}

Background Neonatal Intensive Care Unit (NICU) Discharge Summary (DS) provides continuity of care and ensures safe patient transition between hospital and community. Inadequate NICU DS documentation contributes to medical errors and loss of follow up. Our goal is to improve the DS quality 